\title{
Primary Naso-Sinus Tuberculosis (NST) at the ORL and Cervico Facial Surgery Department of the University Hospital of Cocody: About a Case
}

\author{
N'gouan J. Michel1, Téa Basilide1, Koné Samba², Chatigre Richard1, Abounan Didier33, \\ Adjoua Pascal1 \\ ${ }^{1}$ Otolaryngology and Cervico Facial Surgery of the University Hospital of Cocody, Abidjan, Cote d'Ivoire \\ ${ }^{2}$ Traumatology and Orthopedics Surgery of the University Hospital of Cocody, Abidjan, Cote d'Ivoire \\ ${ }^{3}$ Department of Anatomy-Pathology of the University Hospital of Cocody, Abidjan, Cote d'Ivoire \\ Email: "ngouanorl@yahoo.fr
}

Received 28 January 2016; accepted 11 March 2016; published 14 March 2016

Copyright (C 2016 by authors and Scientific Research Publishing Inc.

This work is licensed under the Creative Commons Attribution International License (CC BY).

http://creativecommons.org/licenses/by/4.0/

(c) (i) Open Access

\begin{abstract}
Objective: To report a case of naso-sinus tuberculosis and discuss its diagnosis and management in our context. Clinical Case: A 37-year-old patient, with no previous history, visited us for a swelling under left orbital including a nasal obstruction and intermittent frontal headaches, which has been developed since about one year. Clinical Examination: The anamnesis founds no notion of epistaxis, visual disability, nor notion of fever. It has been noted a swelling under left angulo orbital during physical examination, a burgeoning mass filling the left nasal including a Lymphadenopathy under homolateral mandibular. Para clinical investigations in particular CT scan of the sinuses have highlighted a tissue process under orbital with a left naso-ethmoido-maxillary extension. The anatomical pathologic examination of the biopsy carried out through endoscopy permitted to highlight epithelioid giganto-cell granulomas with caseous necrosis evoking tuberculosis. The patient has been prescribed an anti-tuberculosis treatment. The course of illness is marked by the healing of the patient.
\end{abstract}

\section{Keywords}

Nasal-Sinus Tuberculosis, Endoscopy, Biopsy

\footnotetext{
${ }^{*}$ Corresponding author.
}

How to cite this paper: Michel, N.J., Basilide, T., Samba, K., Richard, C., Didier, A. and Pascal, A. (2016) Primary Naso-Sinus Tuberculosis (NST) at the ORL and Cervico Facial Surgery Department of the University Hospital of Cocody: About a Case. International Journal of Otolaryngology and Head \& Neck Surgery, 5, 79-83. http://dx.doi.org/10.4236/ijohns.2016.52013 


\section{Introduction}

Tuberculosis (TB) is a top infectious disease killer worldwide. In 2014, 9.6 million people fell ill with TB and 1.5 million died from the disease. Although tuberculosis almost disappeared in better-off countries around thirty years ago, it is becoming a current issue because of its new outbreak and its frequent association with Aids infection [1]. Tuberculosis is an infectious disease, which constitutes a veritable problem of public health inside countries on developing process, where it rages on endemic mode.

Surely predilection siege stays in lungs but it can also affect other extra-pulmonary signs like upper pathways. The localization at the upper pathways, although rare, is estimated at $2 \%$ with patients suffering from active pulmonary tuberculosis [1]. Most of the time, it is a pharyngeal or laryngeal infection, exceptionally nasal, nasopharyngeal or sinus infection [1]. The clinical picture is polymorphic and non-specific, and often a problem of differential diagnosis.

Certitude diagnostic is sometimes late due to an insidious installation; it is based on putting in evidence the germ by bacteriological and/or histological proof on samples.

Its naso-sinus localization is a chronic infection caused by Mycobacterium tuberculosis humanism or bovis, characterized by its rareness and its clinical polymorphism. Therefore, it is often histologically discovered [1].

The treatment is mainly medical. Surgery has no interest and is most of the time associated to a medical treatment in some indications (abscess drainage, diagnostic). We report a case of our primary nasal sinus tuberculosis (NST).

\section{Case Report}

It is about a 37-year-old merchant woman, living in Singrobo (Cote d'Ivoire), with no particular previous history. She has been consulted at the ORL (Otorhinolaryngology) and cervico facial surgery department of the University Hospital of Cocody for a swelling under left orbital including a nasal obstruction and intermittent frontal headaches, which has been developed since about one year.

There has been no notion of tuberculosis contagion, epistaxis, visual disability, nor fever. The patient received an amoxicillin and clavulanic acidbased antibiotic therapy for ten days with no symptomatic improvement. At the beginning of the examination, we noted a swelling under left angular orbital at the front facing the maxillary sinus. It was firm, painless, measuring three centimeters in vertical diameter, fixed to the superficial and deeper structure; the skin facing was healthy (Figure 1). The previous rhinoscopy has shown the presence of a burgeoning mass filling the left nasal cavity, pinkish, firm, not bleeding when touched. We have noted a lymphadenopathy under the left mandibular, of one centimeter, painless, mobile regarding the superficial and deeper structure. Tuberculin intradermal reaction was negative, the chest X-ray was normal, and the Aids serology was negative also.

The CT scan of the sinuses carried, has brought out a tissue process under orbital with a left nasal-ethmoidomaxillary extension (Figure 2) which mentioned: malignant melanoma or epidermoid carcinoma or olfactory neuro-blastoma.

The anatomo-pathological examen of the biopsy carried out through endoscopyshowing a giant epithelial granuloma with central caseous necrosis (Figure 3).

A TB multidrug therapy (Rifampicin, Isoniazid, Ryrazinamide and Ethambutol) was started according to the following regimen: 2 months of RHZE and 4 months of HR, over a period of six months.

We didn't noticed resistance and no secondary effect during treatment.

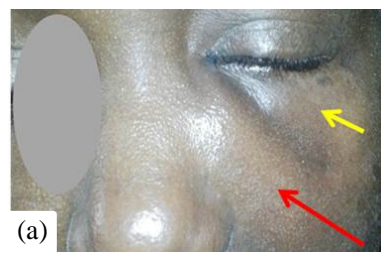

Figure 1. Local appearance of face, a side pré therapeutic view: swelling under left angular-orbital (arrow in red). 


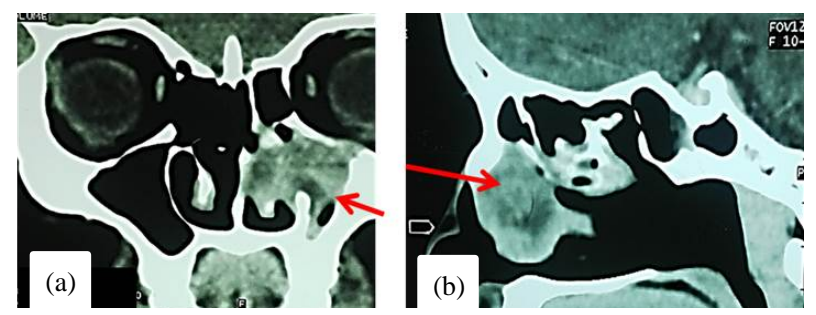

Figure 2. CT scan of nasal-sinus (coronal (a), axial (b)) showing an heterogeneous mass of tissue shape extending to homalatéral sinus ethmoidal and maxillary. The process did not affect the orbital floor (red arrow).

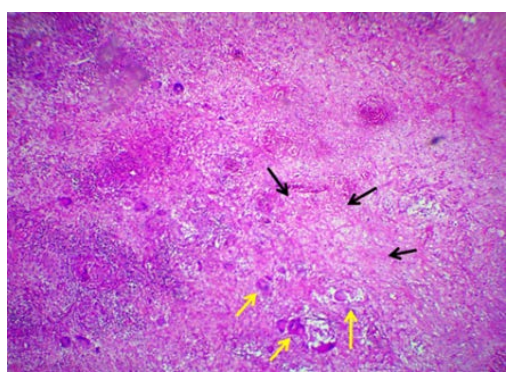

Figure 3. Microscopic appearance of endoscopy biopsy (100 magnifications) showing: granulomatous reaction made of epithelioid cells, Langhans giant cells types (arrows in yellow) and lymphocytic crown centered caseous necrosis (arrow in black).

At 12-month follow-up clinical aspect was satisfactory (clinical involution) (Figure 4), rhinoscopy haven’t evident sign of local recurrence.

\section{Discussion}

Tuberculosis is a chronic infectious disease caused by an acid-fast-resistant bacillus: Mycobacterium tuberculosis humanis or bovis.

Although the extra pulmonary localization is rare, it is estimated at $2 \%$ with patients suffering from pulmonary tuberculosis. And most of the time, it is a pharyngeal or laryngeal localization and exceptionally naso sinus [1].

It may be primary by exogenous inoculation, after nasal scratching or inhalation of bacillus dust; or secondary to pulmonary tuberculosis. Our patient did not show any pulmonary tuberculosis. The rareness of the naso sinus form can be explained by the strong resistance of the nasal mucosa thanks to its mucociliary, bactericidal features and its lymphatic abundance that opposes the development of Mycobacterium tuberculosis. Some local factors (traumatism, chronic rhinitis) or general factors (poor hygiene, silicosis and immunodeficiency) are predisposing [1]. The symptoms often found, are most of the time nasal obstruction, mucopurulent nasal discharge associated with headaches often epistaxis with cervical poly lymphadenopathy [2]-[6]. With our patient, only epistaxis was absent. Several forms of NST are indeed described. The lupus form is characterized by the presence of lupomes, brownish red fine granulations, appearing after an ungual scratching located on the nasal septum, the inferior nasal concha or the floor of the nasal cavity. It is potentially destructive. A septal perforation may be the consequence [1]. The Ulcerous form is the cause of naso sinus ulcerations. The pseudotumorous form, as found in our patient, gives a burgeoning lesion [1], nasal obstruction, mucopurulent nasal discharge associated with headaches. In this form, the CT scan can lead to a misunderstanding directing you towards neoplastic pathologies that if you do not make sure, can cause ungainly surgery.

Certitude diagnosis stays the histological exam by showing giant epithelial granuloma with central caseous necrosis [1]-[4]. In our case, of endonasal endoscopy was contributive to the diagnosis, because permit by biopsy histological diagnosis. 


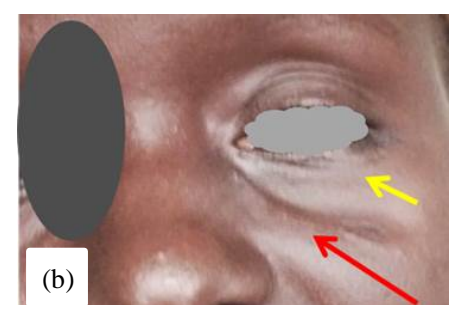

Figure 4. Local appearance of face in post therapeutic view showing a regression of swelling with reappearance of nasolabial fold.

The presence of caseous necrosis is pathognomonic of the tuberculosis and therefore permits to eliminate Wegener's disease and the sarcoidosis. In some contentious cases, we resort to polymerase chain reaction with demonstration of the bacterial deoxyribonucleic acid [1]-[5]. The differential diagnosis is carried out with the other chronic granulomatosis like Wegener's disease, sarcoidosis, leprosy, syphilis, foreign body granulomatosis, epithelioma, actinomycosis, blastomycosis and coccidioidomycosis [1].

Treatment of NST is essentially medical and remains identical to that of pulmonary form. It combines isoniazid (5 to $7 \mathrm{mg} / \mathrm{kg} /$ day) and rifampicin (10 - $20 \mathrm{mg} / \mathrm{kg} / \mathrm{day})$, with pyrazinamide (15 - $30 \mathrm{mg} / \mathrm{kg} / \mathrm{day})$ for three months, replaced by a double therapy based on isoniazid and rifampicin after four to six months. This, in daily dosage or adjusted dosage of twice per week [1]-[5].

Certainly because of its rarity NST therapeutic is not yet well codified. Surgical treatment is no more systematic because of the improvement of the medical; but it's often recommended in bone localizations or giant sinus tumorous forms as was the case for our patient. For some authors, surgery is only aimed at residual lesions [1].

After 12 months we did not observed a local recurrence according with literature (the relapse rate is estimated at $1 \%$ ) [6]. Despite this result, we can occult with certitude the possible apparition of local recurrence. Bouaity had related recurrence case with the emergence of multi-drug resistant strains of BK [7].

\section{Conclusion}

NST is a rare entity and its diagnosis is often difficult to be carried out. In an endemic country as Cote d'Ivoire, the diagnosis should be considered in any chronic and persistent rhinology sign after a well conducted treatment. Certitude diagnosis is histological. The endoscopic exploration combined with biopsy avoids delay in the diagnosis and ungainly surgical approach. The course of illness is favorable with classic anti-TB treatment.

\section{Acknowledgements}

All the authors contributed to the writing of this manuscript and had read and approved final version.

\section{Conflict of interests}

The authors declare no conflict of interest.

\section{References}

[1] Ennouri, A., Hajri, H. and Bouzouaa, N. (1991) Tuberculose des cavités nasales et paranasales. Encycl Méd Chir ORL: 20-375-A-10, 1-8.

[2] Tigoulet, F., Fournier, V. and Caumes, E. (2003) Formes cliniques de la tuberculose cutanée. Bulletin de la Société de Pathologie Exotique, 96, 362-367.

[3] Razafindrakoto, R.M.J., Rakotoarisoa, A.H.N., Ramarozatovo, N.P., Rakotmananjo, A.H., Rakotonirina, T. And Randrianandraina, M.P. (2012) Un cas de tuberculose naso-sinusienne primaire: Une entité rare. La Revue Médicale de Madagascar, 2, 151-153.

[4] Hmidi, M., Elboukhari, A., Touiheme, N., Kettani, M., Rguibi, M. and Messary, A. (2011) Tuberculose nasosinusienne avec extension cutanée: A propos d'un cas. Lettre de pneumologie, XIV, 106-108.

[5] Nitassi, S., Nazih, N., Boujemaoui, M., Essakali, L. and Kzadri, M. (2007) Tuberculose naso-sinusienne: A propos d'un cas. Fr ORL, 93, 347-349. 
[6] Bouchentouf, R., Bouaity, B., Touati, M., Benjelloun, A. and Aitbenasser, M.A. (2013) La tuberculose nasosinusienne primaire à propos d'un cas. Pan African Medical Journal, 14, 29. http://dx.doi.org/10.11604/pamj.2013.14.29.1039

[7] Bouaity, B., Nadour, K., Aljalil, A., Touihem, N., et al. (2009) Tuberculose du naso-pharynx: A proposd'un cas. La Lettre d'oto-rhino-laryngologie et de chirurgie cervico-faciale, 319, 14-16. 